\title{
Migration decision-making and its key dimensions
}

Mathias Czaika, Danube University Krems, Austria

Jakub Bijak, University of Southampton, UK

Toby Prike, University of Southampton, UK

\begin{abstract}
Migration decisions are taken in the context of personal needs and desires while facing uncertainty regarding outcomes of alternative behavioral options. Information about the future and its opportunities is incomplete, and whether migration turns out as a personal success or failure depends mostly on circumstances that are ex ante unknown and ex post not fully under the control of the migration decision-maker. This article elaborates on four dimensions considered as critical in approaching the complex process of migration decisionmaking: first, the formation of migration aspirations, second, the cognitive rules for searching and evaluating information about migratory options, third, the timing and planning horizons for preparing and realizing migratory decisions, and fourth, the locus of control and degree of agency in taking migration decisions. Based on a review of the current state of evidence, we identify avenues for future empirical research addressing knowledge gaps along these key dimensions of migration decision-making.
\end{abstract}

\section{Key words}

Aspirations, Information, Locus of control. Migration decisions, Time horizon, Uncertainty

\section{Contact information}

Mathias Czaika, Danube University Krems, Dr.-Karl-Dorrek-Straße 30, 3500 Krems, Austria. Phone: +43-2732-8932424, Email: Mathias.Czaika@donau-uni.ac.at (corresponding author) Jakub Bijak, university of Southampton, UK. Email: J.Bijak@soton.ac.uk Toby Prike, Universiyt of Southampton, UK. Email: T.M.Prike@soton.ac.uk

\section{Acknowledgements}

This work has received funding from the European Union's Horizon 2020 research and innovation programme; grants No. 870299 QuantMig: Quantifying Migration Scenarios for Better Policy (MC and JB) and 725232 BAPS: Bayesian Agent-Based Population Studies (JB and $\mathrm{TP}$ ). A preliminary version of this paper is available as QuantMig project report D1.3 from www.quantmig.eu. This paper reflects the authors' views, and the Research Executive Agency of the European Commission is not responsible for any use that may be made of the information it contains. 


\section{Introduction}

Understanding migration decisions is of fundamental importance for broader society and policy makers, as well as migrants and potential migrants themselves. Migration decisions are taken at important crossroads in people's lives; determine and are determined by longterm life trajectories; and bring lasting consequences for the decision-maker and people affected by the decisions and subsequent behavioral actions. Migration scholars often presume that due to their relative rarity and long-term implications, migration decisions should be highly rational and characterized by the best possible assessment of costs and benefits. In reality, however, migration decisions are often taken in the context of idiosyncratic personal needs, stress, urgency and - above all - uncertainty and limited information about livelihood opportunities. Information about the future and its opportunities is incomplete, and whether migration turns out to a migrant's benefit or as a real failure depends largely on circumstances that are ex ante unknown and ex post not fully under control of the migrant.

In this paper, we propose a typology of migration decisions cutting across four important dimensions, linked to various migration factors and drivers. We conceptualize the formation of migration aspirations as a largely needs-driven process and as a fundamental prerequisite for self-determined migration decisions. To that end, we first review the state of knowledge regarding migration aspirations formation and adaptation, before specifying established cognitive features and biases that may be influential in migration decision-making. 
Furthermore, we examine migration decisions according to how informed they are and how long the decision-making process takes. On the one hand, migration decision-making can be a highly conscientious multi-step and gradual process of aspiration formation, resource accumulation, search for life and livelihood opportunities, and a decision among wellidentified migratory options. This may ultimately lead to a highly informed, self-determined and comprehensive assessment of multiple forms of costs and benefits, reducing the epistemic uncertainty surrounding the decisions as much as possible. But migration can also be the result of ad hoc decisions based on scarce information and minimal planning and preparation. All forms of migration decisions are surrounded by often very high and possibly irreducible uncertainty and are conceptualized as driven by some simple decision rules (heuristics) and other shortcuts such as imitation, affect, norms and commitments.

We further distinguish migration decisions by the locus of control and the degree of human agency and self-determination. Decisions that are largely externally controlled - for instance by members of the social network, including family, friends, or the community, but also other agents who may for example enforce displacement - embody a limited level of voluntariness, self-determination, and self-efficacy. This dimension extends and refines the established but controversial dichotomy between 'voluntary' and 'forced' migration. It contrasts situations in which prospective migrants with a high-level of agency and self-determination fully control 'internally' the decision-making process and outcome with those where they are at the mercy of external drivers, with a limited number of options.

We begin the discussion by defining the four conceptual dimensions of the migration decision process - formation of aspirations, availability and use of information, time and decision 
horizon, and the locus of control - and discuss each of them in turn (Section 2). We then review the empirical work on migration decisions, based on both experimental and observational studies (Section 3) and conclude by identifying the outstanding knowledge gaps and providing guidance for further research (Section 4).

\section{Dimensions of migration decisions under uncertainty}

One cross-cutting theme of all migration decisions is that they are taken under conditions of high uncertainty with respect to the likelihood and potential outcomes of alternative choices (e.g., Williams and Baláž 2012). Literature often makes a distinction, dating back to Knight (1921), between measurable risk and unmeasurable uncertainty, the latter more difficult to elucidate and manage. Coupled with the lack of knowledge about possibilities and outcomes, this can also lead to situations of ambiguity under risk, or ignorance under uncertainty proper (Stirling 2010). In this paper, however, we use the term uncertainty as an umbrella covering all four possibilities, noting that uncertainty in different guises can be either epistemic reducible in the light of better knowledge and information - or aleatory - immanent and irreducible (e.g., Bijak and Czaika 2020). This is also to avoid a slight terminological confusion with respect to risk, which in the context of cognitive science is often used in the context of uncertain events bearing negative consequences - a convention that we follow throughout this paper.

The field of decision-making under uncertainty is interdisciplinary, covering psychology (Scholz 1983), statistics (Robert 2007), economics (Gilboa 2008), neuroscience (Bland and Schaefer 2012), as well as computer science (Kochenderfer 2015), with many cross-cutting 
themes, as evidenced throughout this Special Issue. At the same time, truly interdisciplinary efforts in the area of migration studies are rare (Vari-Lavoisier 2021). In this paper, we also take an eclectic, multi-disciplinary view to look at the four key dimensions of migration decision-making. We start from the aspirations of prospective migrants at the outset of the decision process, which are mediated by the availability and use of information and the time horizon of decisions, as well as the locus of control - who makes decisions. These four aspects are conceptually separate, as illustrated in Figure 1 delineating a four-dimensional migration decision space; although for real-life decisions, some of these dimensions interact: for example, more information and internal locus of control enables longer planning horizons. These four dimensions are discussed in more detail next.

\section{Figure 1.}

\section{Key dimensions of migration decisions under uncertainty}

Availability and use of information

Level of aspirationsow aspirations

Medium aspirations

High aspirations

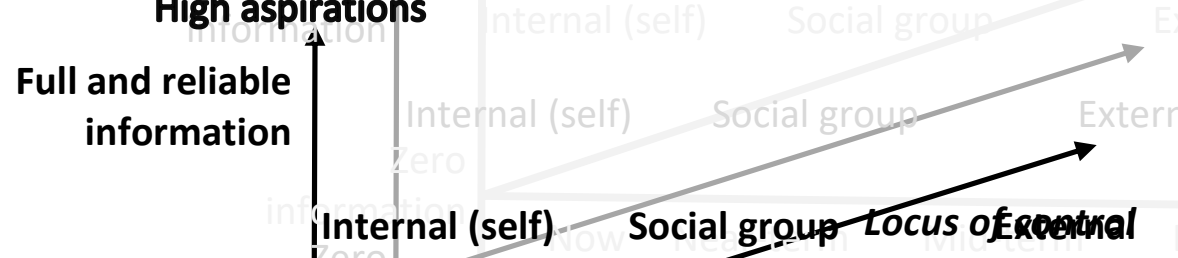

Zero

information

False and

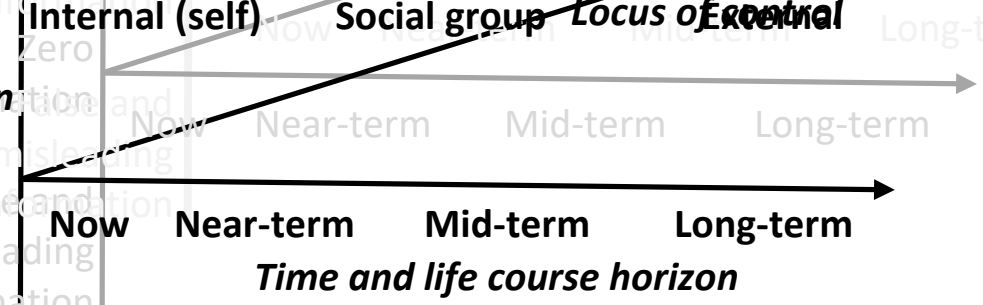

misleading information 


\section{a. Aspirations as precursor of migration decisions}

People of all countries and cultures aspire to life satisfaction, wellbeing, or simply, the 'good life' (Appadurai 2004), which is "not a state to be obtained but an ongoing aspiration for something better that gives meaning to life's pursuits" (Fischer 2014, p.2). Life aspirations are fundamentally nurtured by material and non-material needs including economic, social, cultural, and psychological factors (Maslow 1943, Aslany et al. 2021). External factors become effective in stimulating migration only if they translate into the volition and motivational capacity of people to change locational life circumstances. We therefore conceptualise 'aspirational gaps', i.e., a mismatch of aspired and actual life circumstances, as the internal cognitive driver activating a personal reflection, desire and decision-making process on migration (cf. Greenaway et al. 2015).

Aspirational gaps as the difference between the state of needs satisfaction and individual aspirations are a pre-condition for considering migration as a viable option. While some longterm life goals and moral and ethical values might take years to evolve, other aspirations evolve and change arguably a lot faster and in response to unfulfilled individual needs. Like Maslow's hierarchy of needs, a hierarchy of aspirations exists, where lower aspirations correspond to unmet basic needs. For instance, in the context of food shortages due to a drought or a natural disaster, people's unmet physiological needs may trigger the fundamental aspiration of never feeling hunger again. Immediate food aid might address this need and aspiration, but people may also, particularly during repeated or prolonged periods of food shortages, develop higher aspirations, e.g., to reduce physiological vulnerability of one's family without relying on food aid (see also Amartya Sen's (1981) 'food entitlement' 
theory). In this case, the motivation to change the status quo may also motivate migration as a behavioral option to change one's status quo and to fulfil higher-order aspirations.

Beyond immediate needs, people's aspirations are further influenced by their personality, socialization, and education, all constituting elements of a personal 'capacity to aspire' (Appadurai 2004), which refers to the capacity to imagine a life that is superior but still achievable compared to the status quo. This capacity to aspire is multidimensional and nurtured by a person's economic, social, emotional, and cognitive resources (Sell \& De Jong 1978; Shaw 1974, Frye 2012).

Moreover, aspirations for greater qualities of life are not static but they may change dynamically through external stimuli, such as peer-group interaction, social comparisons of one's own status quo with life situations of 'relevant others' (as postulated by the New Economics of Migration theory, e.g., Stark and Taylor 1985), observation of other ways of living, or simply by exposure to information as transmitted by media and social networks. Migration is often a crucial step in the lifecycle to meet aspired goals and well-being through the pursuit of the 'good life'. The endogenous nature of aspirations is often reflected by the fact that aspirations after migration are usually not the same as before but are often adapted (usually upwards) through exposure to new, so far unknown lifestyles and environments at the place of residence (Czaika \& Vothknecht 2014).

Paradoxically, the adapting of aspirations may trigger a 'hedonic treadmill' effect by which migrants may feel more deprived and unsatisfied in the new environment - even if initial expectations for migrating have largely been met (Czaika \& Vothknecht 2014). People may 
also adapt their life and migration aspirations by incorporating (positive or negative) migration experiences of others through social comparisons and role modelling. Thus, aspirations may not only adapt through one's own experience but also by learning about the achievements, failures, and states of wellbeing of others (Selten 1998). Generally, people usually find it easier to adapt their aspirations upwards and do so more rapidly than adapting downwards ('cognitive ratcheting'); that is, downward corrections of aspirations seem to be perceived as more painful than upward adaptations (Engzell 2019).

\section{b. Information and heuristics in searching and deciding about migratory options}

Information search in the context of migration decision-making is both a multi-stage and multi-dimensional process. The different stages involve collection and processing of information about available migration opportunities including information on potential destinations, possible entry routes, possible job opportunities, but also assessing possible types of risk and uncertainty related to migration journeys and outcomes.

Access and control over various kinds of resources including knowledge and information about the 'good life' and opportunities for its realization are important prerequisites for the formation of migration aspirations. People's awareness of social, economic, political, and other opportunities may therefore increase one's 'capacity to aspire' (Appadurai 2004). The awareness is closely linked to the availability of information on such opportunities. Information might affect the formation and adaptation of life aspirations and perception thereof, but also of more concrete migration opportunities, experiences, and outcomes, including the multifaceted costs and benefits of an actual migratory move. 
Perceptions of expected or actual migration outcomes have functional and cognitiveemotional attributes. Functionality in this context implies that migration can be a means to an end, i.e., instrumental to a higher goal such as improving one's life circumstances. Cognitive and emotional aspects, on the other hand, refer to feelings associated with and characteristics of the migration journey itself, for instance whether it is enjoyable or bothersome, safe or dangerous, necessity or choice. These feelings about anticipated migration experiences are not binary in practice, but rather fluid.

Furthermore, information directly affects life aspirations as people learn about ways of living and opportunities elsewhere. While this proposition is contrary to claims by De Jong and Fawcett (1981) who state that goals and values are independent of information, it seems reasonable to assume that goals, values and aspirations can change; the hedonic treadmill effect being a prime example (Czaika \& Vothknecht 2014). Moreover, information transmitted through media and the internet can affect both aspirations to migrate (Vilhelmson \& Thulin 2013; Thulin \& Vilhelmson 2016) and actual migration behaviour (Farré \& Fasani 2013; Piotrowski 2013). Information might further affect how the link between life aspirations and migration is perceived, i.e., whether migration outcomes have the potential to meet one's aspirations. Information also affects how migration costs and benefits are perceived before embarking on the migration journey (Goodman 1981). Information about expected economic benefits of migration has the potential to affect actual migration behavior (Farré \& Fasani 2013; Gibson et al. 2010; Hugo 2003; McKenzie et al. 2007; Piotrowski 2013). 
For the migration decision itself, information and awareness about potential destinations and respective opportunities is central to establishing a pool, and if evaluated, a hierarchy of potential destinations to choose from (Wolpert 1965, Brown \& Moore 1970). Search for migratory options might be guided by accurate, factual, and objective representations of conditions at potential destinations, but also by imaginations, expectations, and perceptions thereof (Haberkorn 1981; Thompson 2017). Information can therefore affect search behavior directly, but also more indirectly through its impact on aspirations, expectations, and perceptions (McKenzie et al. 2007; Thompson 2017; Volcic \& Erjavec 2013). Neoclassical economic theory states that individuals "try to obtain as much information as possible in order to make the best possible decisions" (Epstein 2008, p.573). However, we also know that increasing the quantity of information beyond a certain amount does not necessarily improve the quality of decisions (Scheibehenne et al. 2010). Rather, too much information can result in a poor, or even no, decision due to cognitive overload (Gigerenzer \& Gaissmaier 2011; Keller \& Staelin 1987; Peters et al. 2013).

The question therefore arises when individuals (should) stop searching for information. According to economic theory, an optimal stopping rule requires that information search should stop once benefits from doing so outweigh the costs (Stigler 1961). While intuitive and simple, this notion of optimally informed decision-making puts an unreasonable burden on decision-makers, as it requires a continued updating of cost-benefit calculations as new information is acquired (Simon, 1955, 1959; Selten, 1998; Gigerenzer, Todd and ABC Research Group, 1999). 
Insights from psychological and behavioral economic research present heuristics and simple decision rules as more realistic alternatives for understanding decision-making under uncertainty (Tversky and Kahneman, 1974; Kahneman and Tversky, 1979, 1984; Gigerenzer, Todd and ABC Research Group, 1999). Heuristics are "methods for arriving at satisfactory solutions with modest amounts of computation", which are often used unconsciously or automatically (Simon, 1990, p. 11). The subconscious use of a heuristic depends on heuristics that are cognitively available to the individual decision-maker. Factors that might affect the available set of heuristics include personality traits, socio-cultural background, and social learning. Selten (1998), for instance, suggests satisficing as a simple search and decision heuristic, which implies that the search process for migratory options is 'stopped' as soon as some satisfactory options are found whose expected outcome is anticipated to reach or surpass a certain minimum level, which is usually less than the aspired level.

Processing migration-related information, i.e., searching, editing, and evaluating migratory options, involves a cognitive assessment of the anticipated challenges and expected consequences of (a few) identified migration options, including the status quo option of nonmigration. The cognitive process of editing and evaluating involves heuristics to simplify, organize, reformulate, order, select, delete and ignore information, e.g., on migration risks and opportunities (Gigerenzer 2015). In contrast with the rational expectation framework used by the neoclassical migration theory (e.g., Harris and Todaro 1970), prospect theory suggests that a migration decision-maker compares and converts perceived or expected absolute outcomes into relative (i.e., reference-dependent) outcomes which are framed as gains or losses relative to a reference point which is often their own status quo (Tversky \& Kahneman 1991, Kahneman and Tversky 1979; on reference points, see also Stark and Bloom 
1985). Evidence shows that these framing effects are indeed affecting migration decisions and broader migration flows (Czaika 2015). The way information is framed or presented does influence the evaluation of migration options, and consequently, migratory action and inaction.

\section{c. Planning horizon and timing of migration decisions}

Migration decisions are situated in time - both historical and individual - and take time. In most instances, the actual migration event is preceded not only by the decision, but also by a period of careful planning and preparations for the actual move. At the same time, migration decisions are anticipatory: they take into account what can be gained by moving in the future, as compared with the counterfactual scenario of staying. From that point of view, migration decisions are clearly an example of intertemporal, as well as spatial choice (for a review of the different aspects of time and temporalities in the migration context, see e.g., Griffiths et al. 2013). Even though the fundamental uncertainty of the future remains aleatory, there are some aspects of it that are epistemic and about which we already can have some knowledge.

Time has several functional roles in migration decisions. One is time preference - a concept going back to the work by Eugen von Böhm-Bawerk and Joseph Schumpeter over a century ago (Anderson 1915) - whereby economic agents prefer current (certain) payoffs over future (uncertain) ones of the same or even somewhat larger magnitude (e.g., Aschheim et al. 1974). There are also a range of psychological studies on time preference, importantly highlighting its dependence on demographic characteristics, such as age or health status (Chao et al. 2009; for an overview, see e.g., Odum 2011). This notion is controlled by using intertemporal 
discounting, with the discount rate describing the degree of time preference. In migration studies, this feature has been reflected chiefly in neoclassical theories and models (e.g., Sjaastad 1962; Borjas 1990; Massey et al. 1993: 435).

The second temporal aspect of migration decisions is related to individual time - the position of agents on their life course trajectories. Known regularities in migration patterns by age (Rogers and Castro 1978) are linked with other life course-based individual decisions, such as childbearing, education or employment, as well as preferences and constraints (Courgeau 1985). Life course aspects can also manifest themselves in choices between alternative destinations (de Jong and de Valk 2020). Of temporal relevance is the economic distinction between transitory and permanent income (Friedman 1957), where the decisions may be either driven by current income status, or future expectations, averaged over the life course to account for income and expenditure differences between the successive stages of life.

Third, migration decisions take time and are stepwise processes. At a general level, this aspect is explicitly recognized. For example, the theory of planned behavior (Ajzen 1991) describes how an interplay of norms, attitudes and control leads to the formation of intentions, which in turn trigger decisions and drive actual human behavior. In the context of migration, Lu (1998) has used the theory of planned behavior, coupled with the theory of reasoned action to examine migration decisions based on survey data. Similarly, Kley (2017) used this framework to identify different stages of the decision process and Klabunde et al. (2017) applied it to an agent-based simulation model of migration. In this context, it is worth noting that intentions may be seen as a potential predictor of migration behavior (van Dalen 
and Henkens 2013), but one that is obviously limited: intentions are a necessary, but not a sufficient condition for human action.

\section{d. Self-determination and locus of control of migration decision-making}

The final dimension in our typology is the locus of control and level of self-determination in migration decision-making. Here again, we posit the existence of a spectrum, from decisions made chiefly by the migrants themselves, through group-based decisions, to external locus of control in the form of broader social and political forces. Most neoclassical models of migration decisions (e.g., Harris and Todaro 1970) are monadic with respect to decisionmaking in that the decision unit is an individual agent who decides whether to migrate or not. Other perspectives, such as the world systems theory (Wallerstein 1974), see migration chiefly as a product of interacting high-level macroscopic social, political, and historical forces. When it comes to the impact on individual decisions, this viewpoint is particularly pronounced in the case of forced migration and persecution, where the individual locus of control is substantially diminished.

The relevance of groups, such as families or households, came into the foreground with the work of Mincer (1978) on family migration decisions and the development of the New Economics of Migration theory (e.g., Stark and Taylor 1985). These ideas were further developed by others - for example, Borjas and Bronas (1991) showed the importance of household composition, whereas Haug (2008) extended the discussion to situate decisions in a broader context of social networks and social capital. The common thread is that families or households not only try to maximize income through migration of (some of) their 
members, but also use migration as a tool for managing financial and employment risk by spreading labor activities across different markets. At the same time, from the sociological and demographic points of view, the group-level locus of control is clearly linked with the life course and household and family composition (e.g., the presence of children), as discussed previously (Courgeau 1985; de Jong and de Valk 2020).

In this way, the level of self-determination interacts with time and aspirations, so that an internal locus of control is - ceteris paribus - associated with higher aspirations, longer planning, and decision horizons. A conjecture here, which requires further empirical investigation, is that the key underlying factor (or, latent variable), influencing all four dimensions of migration decisions - including the demand for information - is related to individual attitudes to risk and uncertainty. Attitudes to risk have long been subject to experimental studies in psychology, and more recently within the context of migration decision-making. The emerging empirical evidence, reducing the epistemic uncertainty of human migration decisions somewhat, is discussed in the next section.

\section{Migration decision-making: selected empirical evidence}

Experimental approaches, in the style of work conducted in psychology and behavioral economics, are an effective but rarely utilized approach for building greater understanding of migration decision-making (Baláž \& Williams 2017). For example, experimental approaches can provide insight into migration decision-making by (i) examining differences between migrants and non-migrants; (ii) examining hypothetical migration decisions within a controlled environment that allows for manipulation of variables (e.g., framing of decisions, 
attributes of destination country, changes in policy etc.); and (iii) by testing for changes before and after migration (although see Arenas et al. 2009 and Beauchemin et al. 2011 for discussions about potential difficulties and biases when attempting to track migrants across borders).

The role of risk attitudes is an area that has been of particular focus when examining individual differences between migrants and non-migrants. Although not all research that examined this question has been experimental, measures and tasks from psychology and behavioral economics have regularly been used. Across several studies, using varied measures of risk tolerance, researchers have found that those who migrate are more tolerant of risk and uncertainty than non-migrants (Akgüç, Liu, Tani, \& Zimmermann 2016; Dustmann et al. 2017; Gibson \& McKenzie 2011; Jaeger et al. 2010; Williams \& Baláž 2014).

Of course, how to define and measure risk remains a contentious issue: in the context of migration, this is amplified by the need to reflect both risk and losses related to life and limb (in the case of forced migration), as well as those related to income and livelihood (economic migration). Measures attempting to reconcile both aspects exist (such as the Risk Number; Duckworth 2015), but nonetheless, the commensurability of diametrically different aspects of risk faced by prospective migrants and non-migrants remains problematic.

In an early experiment within the field of migration, Baláž and Williams (2011) examined tolerance for risk and uncertainty using gambling tasks in a laboratory experiment. The study included both migrants and non-migrant participants, finding that female migrants were more risk taking than non-migrants. However, there were no significant differences between 
male migrants and non-migrants, possibly due to the tendency for males to be more risk taking in general (Byrnes et al. 1999). Ceriani and Verme (2018) and Mironova et al. (2019) also examined risk tolerance for migrant and non-migrants using gambling tasks, however, they focused on migration away from conflict zones and found that those stayed were more risk tolerant than those who migrated. These findings are in the opposite direction to the more general finding that migrants are more risk taking and highlight the important role of context for migration decisions.

The question of whether migrating changes risk attitudes has also been examined through experiments. In a longitudinal study, Gibson et al. (2019) used both survey and gambling tasks to measure the effect of migrating on risk tolerance and time preferences (e.g., willingness to delay an immediate pay off to receive a larger pay off in one year). They found that these preferences were stable over time, with no significant changes in risk or time attitudes occurring as a result of migrating.

Cumulatively, this line of empirical research highlights that tolerance for risk and uncertainty are indeed key individual attributes relevant for the decision to migrate. When making a choice to migrate for economic or other reasons, deciding to migrate into an unknown situation requires considerable risk-taking, and therefore, those who are more tolerant of risk are more likely to migrate. However, if living conditions in the current location have deteriorated because of conflict and/or other dangers, then deciding to migrate may be the least risky option because it allows for an escape from danger. Regardless of the actual reasons for migrating, and under any circumstances at a particular location, there is considerable variation in relevant decision factors between individual migrants. Moreover, 
judgements about risks and opportunities are subjective which introduces even greater variation between individuals.

Furthermore, lab experiments have been used to examine the applicability of prospect theory (Tversky and Kahneman 1992, see also Section 2b) to migration decision-making. Here, Bocquého et al. (2018) elicited measures related to the prospect theory from asylum seekers in Luxembourg, finding support for propositions of the theory. Clark and Lisowski (2017, 2019) combined prospect theory in the context of migration with other sociological and psychological notions, such as social capital or the endowment effects. A recent study (Prike et al., 2018) elicited utility and risk aversion in a migration context, framed as choices between destination countries. They found that loss aversion was present in the migration context and that participants showed diminished sensitivity for gains, indicating that the prospect theory is applicable to migration decision-making at the level of individuals. Czaika (2015) has shown that prospect theory is applicable to explaining migration processes at the level of populations (see also earlier economic work on similar topics, for example by Katz and Stark 1986). Empirical work on prospect theory and other formalized theories can be applied to models and simulations to generate further insights and greater understanding of migration (Jager 2017; Klabunde \& Willekens 2016).

In addition, the role of information in migration decision-making can also be examined by using experimental methods. In a series of laboratory experiments, Baláž et al. (2016) and Baláž and Williams (2018) investigated how people, both with and without previous migration experience, conduct information search to inform migration decisions. They found that potential migrants are most likely to request information about economic factors such 
as wages and living costs and that these factors are most important in the destination choice. They further find that migrants are more likely than non-migrants to request information about quality of life, suggesting that migration experience may lead people to place more emphasis on non-economic factors.

Also experimentally exploring the role of information in migration decision-making, Prike et al. (2020) provided participants with information about the safety of traveling within two migration contexts, a boat journey across the sea and an internal migration journey to stay with loved ones during a pandemic. This study provided insight into how people respond to information from different sources as well as how they aggregate this information together to form overall judgements and decisions.

\section{Knowledge gaps and ways forward}

This article demonstrated that the relatively new but rapidly growing body of theoretical and empirical research on migration decision-making has the potential to generate insights and provide greater understanding of individual differences in cognitive decision-making processes. However, there is more work to be done both conceptually and empirically; on the basis of robust empirical evidence, we will also see necessary adaptations to theories explaining complex migration decision-making processes.

The broad range of already existing empirical studies clearly demonstrate the potential of survey-based experiments and other micro-level analyses to provide insight into the process of migration decision-making. For instance, by employing vignette and scenario-based 
studies that experimentally manipulate the decision environment or context, we may learn more about the cognitive processing of information, risk, and opportunities relevant for migration decisions. From a cognitive science perspective, we still have inconclusive answers regarding why some people decide to migrate while others stay, or what the impacts of the migration experience are on migrants' cognition. While conceptual and empirical interest in migration decision-making and certain aspects of it such as the role of aspirations or risk attitudes seems to be steadily growing, we still see relatively little work on the more complex interplay between the dimensions discussed in this article. In addition, the links between attitudes to risk and the four dimensions of migration decisions are still in need of further and deeper empirical investigation.

Despite the focus of different strands of research on aspects such as aspirations, information, temporality, or human agency in decision-making, the fact that these dimensions are closely interconnected has hardly been addressed in the literature. For instance, we know that formation of aspirations is associated with the life cycle and that access to certain informational and educational resources enhances the capacity to aspire. At the same time, we are unclear how the locus of control and degree of agency are interlinked not only with life cycle stages but also with the quality and quantity of information available to take selfdetermined decisions. Or, if the locus of control is external and comes with the strong influence of the family, friends or social community, how does this interlink with the aspirations of the collective rather than of the individual when it comes to migrating, or not? These aspects bring about additional empirical challenges in the need to design a robust way to assess collective - as opposed to strictly individual - decisions in an experimental setting. This could be done by sampling groups (such as families or households) and carrying out 
experiments on different members of the group, in a similar way to survey-based studies, where sampling is often performed on the household basis, and then responses are recorded for all individuals in a household. This would enhance the analytical possibilities by applying multi-level modelling at the individual and group level.

Furthermore, relatively little is known about how emotions and gut feelings interfere with cognitive processes of rationalization when it comes to evaluating, and ultimately, deciding about migratory options. New and emerging technologies may offer opportunities to overcome some of these limitations. For instance, the use of virtual reality has already shown promising results in areas such as pedestrian behavior and traffic management (Arellana et al. 2020; Farooq et al. 2018; Rossetti \& Hurtubia 2020), emergency evacuations (Arellana et al. 2020; Moussaïd et al. 2016), and across a variety of domains in economics and psychology (for a review, see Mol 2020). Technologies such as these provide opportunities for more immersive and engaging experimental designs, allowing for a more thorough exploration of the role of emotions and other factors in migration decision-making. Whether the findings from such studies can lead to establishing causal links between psychological traits and different dimensions of migration decisions, as opposed to mere associations, remains an open question.

Addressing all these questions, and more, in a conceptually sound and empirically robust way, and examining the potential of different factors for either confounding or mediating the relationship between the underlying migration drivers and their cognition, offers a fascinating research agenda, bearing substantial promise to reduce the epistemic uncertainty about migration decision-making processes. 


\section{References}

Ajzen, Icek. 1991. The theory of planned behavior. Organizational Behavior and Human Decision Processes 50(2): 179-211.

Akgüç, Mehtap, Xingfei Liu, Massimiliano Tani, and Klaus F. Zimmermann. 2016. Risk attitudes and migration. China Economic Review 37: 166-176.

Anderson, Benjamin M. Jr. 1915. Schumpeter's Dynamic Economics. Political Science Quarterly 30(4), 645-660.

Appadurai, Arjun. 2004. The Capacity to Aspire: Culture and the Terms of Recognition. In M. Walton \& V. Rao, eds. Culture and Public Action: A Cross-Disciplinary Dialogue on Development Policy. World Bank Publications, pp. 59-84

Aschheim, Joseph, Vito Tanzi, and Ralph K. White. 1974. Time preference: A psychological concept in economics. Journal of Behavioral Economics 3, 111-125.

Aslany, M; Carling, J; Mjelva, MB; Sommerfelt, T (2021) Systematic review of determinants of migration aspirations. QuantMig Project Deliverable D2.2. Southampton: University of Southampton

Baláž, Vladimir, and Allan M. Williams. 2011. Risk attitudes and migration experience. Journal of Risk Research 14(5): 583-596. 
Baláž, Vladimir, Allan M. Williams, and Elena Fifekova. 2016. Migration decision making as complex choice: Eliciting decision weights under conditions of imperfect and complex information through experimental methods. Population, Space and Place, 22: 36-53.

Baláž, Vladimir and Allan M. Williams. 2017. Experimental Research Methods in Migration: From Natural to True Experiments. Population, Space and Place, 23: e1974.

Baláž, Vladimir and Allan M. Williams. 2018 Migration decisions in the face of upheaval: An experimental approach. Population, Space and Place, 24: e2115.

Bijak, Jakub and Mathias Czaika. 2020. Assessing Uncertain Migration Futures - A Typology of the Unknown. QuantMig Project Deliverable D1.1. University of Southampton \& Danube University Krems. Available via www.quantmig.eu (accessed 1 October 2020).

Bland, Amy R, and Alexandre Schaefer. 2012. Different varieties of uncertainty in human decision-making. Frontiers in Neuroscience 6: 85. DOI: 10.3389/fnins.2012.00085

Bocquého, Géraldine, Marc Deschamps, Jenny Helstroffer, Julien Jacob, and Majlinda Joxhe. 2018. Risk and Refugee Migration. Sciences Po OFCE Working Paper hal-02198118. Paris, France.

Borjas, George J., and Stephen G. Bronars. 1991. Immigration and the Family. Journal of Labor Economics 9(2): 123-148. 
Byrnes, James P., David C. Miller, and William D. Schafer. 1999. Gender differences in risk taking: A meta-analysis. Psychological Bulletin 125(3): 367-383.

Ceriani, Lidia and Paolo Verme. 2018. Risk preferences and the decision to flee conflict. Policy Research Working Paper No. 8376. World Bank, Washington, DC.

Chao, Li-Wei, Helena Szrek, Nuno Sousa Pereira, and Mark V. Pauly (2009). Time preference and its relationship with age, health, and survival probability. Judgment and Decision Making 4(1), 1-19.

Clark, William A. V., and William Lisowski. 2017. Prospect theory and residential decisions. Proceedings of the National Academy of Sciences 114(36): E7432-E7440.

Clark, William A. V., and William Lisowski. 2019. Extending the human capital model of migration: The role of risk, place, and social capital in the migration decision. Population, Space and Place 25: e2225.

Courgeau, Daniel. 1985. Interaction between Spatial Mobility, Family and Career Life Cycle: A French Survey. European Sociological Review 1(2): 139-162.

Czaika, M. \& Vothknecht, M., 2014. Migration and aspirations - are migrants trapped on a hedonic treadmill? IZA Journal of Migration, 3(1). 
Czaika, Mathias. 2015. Migration and Economic Prospects. Journal of Ethnic and Migration Studies 41(1), 58-82.

de Jong, Petra W., and Helga de Valk. 2020. Intra-European migration decisions and welfare systems: The missing life course link. Journal of Ethnic and Migration Studies, 46(9), 17731791.

Duckworth, Frank C. 2015. A One-Dimensional Scale to Compare Risks from Exposure to Various Hazards. Safety and Reliability 35(1): 5-19.

Dustmann, Christian, Francesco Fasani, Xin Meng, and Luigi Minale. 2017. Risk attitudes and household migration decisions, IZA Discussion Papers No. 10603. Institute for the Study of Labor (IZA), Bonn, Germany.

Engzell, Per. 2019. Aspiration squeeze: the struggle of children to positively selected immigrants. Sociology of Education, 92(1), 83-103.

Epstein, Gil S., 2008. Herd and network effects in migration decision-making. Journal of Ethnic and Migration Studies, 34(4), pp.567-583

Friedman, Milton. 1957. A Theory of the Consumption Function. Princeton, NJ: Princeton University Press. 
Frye, Margarete. 2012. Bright futures in Malawi’s new dawn: Educational aspirations as assertions of identity. American Journal of Sociology, 117(6), 1565-1624.

Gigerenzer, Gerd, Todd, P.M. \& ABC Research Group, 1999. Simple Heuristics That Make Us Smart, Oxford: Oxford University Press.

Gigerenzer, Gerd. 2015. Simply Rational: Decision Making in the Real World, Oxford: Oxford University Press.

Gilboa, Itzhak. 2009. Theory of Decision under Uncertainty. Cambridge: Cambridge University Press.

Gibson, John and David McKenzie. 2011. The microeconomic determinants of emigration and return migration of the best and brightest: Evidence from the Pacific. Journal of Development Economics 95: 18-29.

Gibson, John, David McKenzie, Halahingano Rohorua, and Steven Stillman. 2019. The longterm impact of international migration on economic decision-making: Evidence from a migration lottery and lab-in-the-field experiments. Journal of Development Economics 138: 99-115.

Greenaway, Katherine H., Frye, Margarete, \& Tegan Cruwys. 2015. When aspirations exceed expectations: quixotic hope increases depression among students. PloS one, 10(9), e0135477. 
Griffiths, Melanie, Ali Rogers, and Bridget Anderson. 2013. Migration, Time and Temporalities: Review and Prospect. COMPAS Research Resources Paper. Oxford: COMPAS.

Harris, John R., and Michael P. Todaro. 1970. Migration, Unemployment and Development: A Two-Sector Analysis. American Economic Review 60 (1): 126-142.

Haug, Sonja. 2008. Migration Networks and Migration Decision-Making. Journal of Ethnic and Migration Studies 34(4): 585-605.

Jaeger, David A., Thomas Dohmen, Armin Falk, David Huffman, Uwe Sunde, and Holger Bonin. 2010. Direct evidence on risk attitudes and migration. The Review of Economics and Statistics 92(3): 684-689.

Kahneman, Daniel and Amos Tversky. 1979. Prospect Theory: An Analysis of Decision under Risk. Econometrica 47: 263-291.

Katz, Eliakim, and Oded Stark. 1986. Labor Migration and Risk Aversion in Less Developed Countries. Journal of Labor Economics 4(1): 134-149.

Klabunde, Anna, Sabine Zinn, Frans Willekens, and Matthias Leuchter. 2017. Multistate modelling extended by behavioural rules: An application to migration. Population Studies 71(S1): 51-67. 
Kley, Stefanie. 2017. Facilitators and constraints at each stage of the migration decision process. Population Studies 71(S1): 35-49.

Knight, Frank H. 1921. Risk, Uncertainty, and Profit. Boston MA: Hart, Schaffner and Marx; Houghton Mifflin.

Kochenderfer, Mykel J. 2015. Decision Making Under Uncertainty: Theory and Application. Cambridge, MA: MIT Press.

Lu, Max. 1998. Analyzing Migration Decisionmaking: Relationships between Residential Satisfaction, Mobility Intentions, and Moving Behavior. Environment and Planning A 30(8): 1473-1495.

Maslow, Abraham H. 1943. A theory of human motivation. Psychological Review, 50(4): 370-396.

Massey, Douglas S., Joaquin Arango, Graeme Hugo, Ali Kouaouci, Adela Pellegrino, and J. Edward Taylor. 1993. Theories of International Migration: A Review and Appraisal. Population and Development Review 19(3): 431-466.

Mincer, Jacob. 1978. Family Migration Decisions. Journal of Political Economy 86(5), 749773.

Mironova, Vera, Loubna Mrie, and Sam Whitt. 2019. Risk tolerance during conflict: Evidence from Aleppo, Syria. Journal of Peace Research 56(6): 767-782. 
Odum, Amy L. 2011. Delay Discounting: I'm a $k$, You're a $k$. Journal of the Experimental Analysis of Behaviour 96(3): 427-439.

Prike, Toby, Jakub Bijak and Philip A. Higham. 2018. Eliciting Utility Functions for Migration Decisions. Paper for the workshop "Uncertainty and Complexity of Migration", 20-21 November 2018, London. Available from www.southampton.ac.uk/baps/news/events/2018/11/2018-1120-workshop-london.page? (accessed 1 October 2020).

Prike, Toby, Jakub Bijak and Philip A. Higham. 2020. How safe is this trip? Judging personal safety in a pandemic based on information from different sources. Manuscript submitted for publication.

Robert, Christian P. 2007. The Bayesian choice. From Decision-Theoretic Foundations to Computational Implementation. Second edition. New York: Springer.

Rogers, Andrei, and Luis J. Castro. 1981. Model Migration Schedules. IIASA Report RR8130. Laxenburg: International Institute for Applied Systems Analysis.

Scheibehenne, B., Greifeneder, R. \& Todd, P.M., 2010. Can There Ever Be Too Many Options? A Meta-Analytic Review of Choice Overload. Journal of Consumer Research 37: 409-425.

Scholz, Ronald W. 1983. Introduction to Decision Making Under Uncertainty: Biases, Fallacies, and the Development of Decision Making. Advances in Psychology 16(1), 3-18. 
Selten, Reinhard. 1998. Features of experimentally observed bounded rationality. European Economic Review, 42, pp.413-436.

Sen, Amartya. 1981. Poverty and Famines: An Essay on Entitlement and Deprivation. Oxford: Clarendon Press.

Simon, Herbert A. 1955. A Behavioral Model of Rational Choice. The Quarterly Journal of Economics, 69(1), pp.99-118.

Simon, Herbert A. 1990. Invariants of Human Behavior. Annual Review of Psychology, 41, pp.120.

Simon, Herbert A. 1959. Theories of Decision-Making in Economics and Behavioral Science. The American Economic Review, 49(3), pp.253-283.

Sjaastad, Larry A. 1962. The Costs and Returns of Human Migration. Journal of Political Economy 70(5): 80-93.

Stark, Oded, and David E. Bloom. 1985. The New Economics of Labor Migration. The American Economic Review 75(2): 173-178.

Stirling, Andy. 2010. Keep it complex. Nature 468, 1029-1031. 
Tversky, Amos, and Daniel Kahneman. 1992. Advances in prospect theory: Cumulative representation of uncertainty. Journal of Risk and Uncertainty 5: 297-323.

Van Dalen, Hendrik P., and Kène Henkens. 2013. Explaining emigration intentions and behaviour in the Netherlands, 2005-10. Population Studies 67(2): 225-241.

Vari-Lavoisier, Ilka. 2021. Minds on the move: Crossing disciplines to shed new light on human cognition. Wiley Interdisciplinary Review of Cognitive Science 12(1): e1548. DOI: 10.1002/wcs.1548.

Wallerstein, Immanuel. 1974. The Modern World-System I: Capitalist Agriculture and the Origins of the European World-Economy in the Sixteenth Century. New York: Academic Press.

Williams, Allan M., and Vladimir Baláž. 2012. Migration, Risk, and Uncertainty: Theoretical Perspectives. Population, Space and Place 18(2): 167-180.

Williams, Allan M., and Vladimir Baláž. 2014. Mobility, risk tolerance and competence to manage risks. Journal of Risk Research, 17(8): 1061-1088. 


\section{Bios}

Mathias Czaika is a Professor in Migration and Integration and Head of Department for Migration and Globalization at Danube University Krems, Austria. His research focuses on drivers, policies, processes of migration in the context of globalization, development, and inequality. He currently works on the QuantMig (www.quantmig.eu) and MIGNEX (www.mignex.org) project.

Jakub Bijak is a Professor of Statistical Demography and Joint Head of Department of Social Statistics and Demography at the University of Southampton, UK. His research focuses on applying quantitative methods to illuminate uncertainty in population and migration studies. He leads the Bayesian Agent-Based Population Studies and QuantMig projects (www.quantmig.eu).

Toby Prike is a Research Fellow in the Department of Social Statistics and Demography at the University of Southampton, UK. His research background is in psychology, with specific focuses on judgement and decision-making, reasoning, non-evidence based beliefs, and metacognition. He currently works on the Bayesian Agent-Based Population Studies project. 